\title{
Analisis Lokasi, Keberagaman Produk, Harga dan Perilaku Konsumen dengan Minat sebagai moderasi terhadap Kepuasan Konsumen Muslim
}

\author{
Ifan arin \\ Pasca Sarjana Ekonomi Syariah IAIN Salatiga \\ ifanarin17@gmail.com \\ Wiyono \\ Pasca Sarjana Ekonomi Syariah IAIN Salatiga \\ yogawiyono78@gmail.com
}

\begin{abstract}
Abstrak
Pertumbuhan ekonomi syariah baik di pasar tradisional maupun pasar modern semakin berkembang dan kuat. Konsumen muslim yang merupakan salah satu pelaku dalam perputaran ekonomi syariah di pasar. Dalam hal ini faktor apa saja yang mempengaruhi kepuasan konsumen muslim tersebut. Penelitian ini menggunakan metode kuantitatif, variabel independen yaitu lokasi (X1), keberagaman produk (X2), harga (X3) dan perilaku konsumen muslim (X4). Sedangkan Minat (Z) digunakan sebagai variable moderating, untuk kepuasan konsumen sebagai variable dependen (Y). Penelitian ini sebanyak 97 responden dari konsumen muslim yang berasal dari beberapa toko yang dijadikan lokasi penelitian. Dari hasil penelitian ini bahwa peran minat memperkuat pengaruh lokasi sebesar t hitung -3.893 signifikan 0,00 dan minat juga memperkuat harga terhadap kepuasan konsumen sebesar $t$ hitung $-2,682$ dan signifikan 0,009 , sedangkan minat tidak berpengaruh terhadap variabel keberagaman produk dengan $t$ hitung sebesar $-1,440$ dan signifikan 0,153 dan minat juga tidak berpengaruh terhadap perilaku konsumen muslim dengan $\mathrm{t}$ hitung sebesar -1,892 dan signifikan 0,072
\end{abstract}

Kata Kunci Mediator minat, perilaku konsumen, kepuasan konsumen

\section{PENDAHULUAN}

Salah satu motor penggerak ekonomi suatu negara adalah perdagangan. Aktifitas perdagangan merupakan aktifitas yang berpengaruh besar dalam kehidupan masyarakat termasuk di dalamnya segi ekonomi dan politik. Manakala dalam suatu negara memiliki aktifitas bisnis perdagangan yang baik maka ekonomi negara tersebut juga akan mengalami peningkatan. Oleh karena itu, bisnis perdagangan merupakan salah satu faktor ukuran kemajuan ekonomi suatu negara.

Bisnis perdangangan memiliki berbagai macam jenis transaksi, misalnya jual beli. Dalam sebuah bisnis, jual beli tidak bisa dilepaskan dalam aktivitas perdagangan. Dalam Agama juga amat digalakkan umatnya untuk berusaha demi meningkatkan penghasilandan salah satu cara untuk menaikkan taraf ekonomi adalah berniaga sesuai dengan kehendak syariah.

Islam telah mengajarkan bahwa aktifitas ekonomi tidak dapat dilepaskan dari nilai-nilai dasar yang telah ditetapkan dalam al-Qur'an, hadis Nabi dan sumber-sumber ajaran Islam lainnya, sebagaimana ekonomi konvensioanal ekonomi Islam juga membicarakan tentang aktifitas manusia dalam mendapatkan dan mengatur harta material ataupun non material dalam rangka memenuhi kebutuhan hidup sebagai manusia baik secara individual maupun kolektif. Bisnis 
merupakan jumlah dari semua total usaha yang meliputi produksi, pertania, distribusi komunikasi, usaha jasa kepada konsumen.

Prinsip-prinsip syariah adalah suatu aturan atau kebijakan dalam perjanjian yang didasarkan pada suatu etika dalam bisnis Islam yang terjadi antar pebisnis dengan konsuemn untuk melakukan suatu kegiatan bisnis berdasarkan syariat Islam. Prinsip-prinsip syariah tersebut meliputi prinsip keadilan, prinsip al-ihsan (berbuat kebaikan), prinsip al-Mas'iliyah (accountability, pertanggungjawaban), prinsip al-Kifayah, prinsip keseimbangan dan prinsip kejujuran dan keberanian.

Dari prinsip syariah tersebut, maka gambaran secara umum dapat diartikan sebagai segala sumber daya dalam ekonomi Islam dipandang sebagai titipan atau pemberian dari Allah Swt yang diperuntukkan bagi umat manusia selaku pemimpin di muka bumi. Islam mengakui kepemilikan pribadi namun terdapat batasan-batasan, kekuatan utama penggerak ekonomi Islam adalah kerjasama antar sesama umat muslim. Islam menjamin kepemilikan masyarakat dan penggunanya direncanakan untuk kepentingan orang banyak, bagi individu pemilik kekayaan pribadi harus berperan sebagai kapital produksi yang bertujuan untuk meningkatkan kesejahteraan masyarakat muslim dan Islam melarang setiap pembayaran yang mengandung riba.

Oleh karena itu pada penelitian ini berusaha menyajikan data dari beberapa toko yang mengelola usaha toko tradisional secara syariah di sekitar kota Salatiga, sehingga peneliti tertarik untuk mengkaji lebih dalam agar bisa meneliti sejauh mana konsep syariah yang dilakukan bisa bertahan di era modern seperti adanya minimarket atau bahkan supermarket di sekitar Salatiga.

Dengan adanya pertimbangan dan kajian diatas maka perlu adanya analisis lokasi, keberagaman produk, harga dan perilaku konsumen dengan minat sebagai mediator terhadap kepuasan konsumen muslim"

\section{METODE PENELITIAN}

\section{A. Jenis penelitian}

Penelitian ini menggunakan jenis penelitian kuantitatif. Dalam penelitian ini menanyakan ke beberapa orang atau berikutnya disebut responden, tentang suatu keyakinan, pendapat, karakteristik sesuatu obyek.

Pendekatan penelitian yang digunakan adalah pendekatan penelitian hubungan/Asosiatif, yang bertujuan untuk mengetahui hubungan antara dua variabel atau lebih dalam penelitian. Dalam memberikan definisi bahwa penelitian yang dilakukan pada populasi besar maupun kecil tetaoi data yang dipelajari adalah data dari sampel yang diambil dari populasi tersebut.

\section{B. Lokasi penelitian}

Adapun obyek penelitian ini dilakukan di Toko Sembako 39 Salatiga dan Toko Haji Untung Salatiga. Waktu penelitian akan kami lakukan pada periode bulan Desember 2019 sampai Februari tahun 2020.

\section{Populasi dan sampel}

1. Populasi Islam.

Populasi dalam penelitian ini adalah pengunjung di toko dan pelanggan yang beragama

\section{Sample}

Dikarenakan jumlah populasi tidak diketahui secara pasti maka untuk menentukan besarnya sample digunakan rumus unknown population. Dari perhitungan tersebut maka diketahui besar sampel yang diperlukan adalah 97 responden.

\section{Metode pengumpulan data}


Pengumpulan data dalam penelitian ini melalui angket dan kuesioner kepada konsumen sambil memberikan pengertian dan arahan apabila terdapat pertanyaan yang diajukan dalam kuesioner. Pertanyaan yang dimuat dalam kuesioner terkait variabel lokasi, harga keberagaman produk dan minat beli yang datanya akan dikumpulkan untuk diolah.

\section{E. Tehnik pengolahan dan analisis data}

Analisis menggunakan metode kuantitatif, diharapkan akan mendapatkan pengukuran yang lebih akurat tentang tanggapan dari para responden, sehingga data yang berbentuk angka tersebut dapat diolah dengan menggunakan metode Spss dengan memasukkan hasil dari operasional variabel yang akan diuji.

\section{F. Hipotesis Penelitian}

Hipotesisi dalam penelitian ini menunjukkan bahwa Store atmosphere berpengaruh positif terhadap keputusan pembelian konsumen, lokasi toko berpengaruh positif terhadap keputusan konsumen untuk membeli. Pengaruh lokasi, harga fasilitas dan kualitas pelayanan terhadap kepuasan konsumen, terdapat pengaruh positif signifikan antara lokasi, harga, fasilitas dan kualitas pelayanan terhadap kepuasan konsumen. Dari pernyataan diatas dapat ditarik hipotesis bahwa semakin strategis lokasi usaha dan tingginya minat beli maka akan semakin tinggi kepuasan konsumen.

Produk yang beragam akan mempengaruhi minat konsumen karena variasi produk yang ditawarkan akan memberikan presepsi yang menarik dan lebih lengkap bagi konsumen yang akan memutuskan untuk membeli produk yang diinginkan. Lokasi tidak berpengaruh positif terhadap minat beli, sedangkan keberagaman produk dan harga berpengaruh positif dan signifikan terhadap minat beli konsumen. Secara simultan ada pengaruh keragaman produk kualitas produk dan lokasi penjualan terhadap kepuasan konsumen, secara simultan terdapat pengaruh keberagaman produk kualitas produk dan lokasi penjualan. Maka dari beberapa pernyataan diatas, maka dirumuskan hipotesis yaitu semakin banyak ragam produk barang yang disajikan dan tingginya minat beli maka semakin tinggi kepuasan konsumen.

Harga yang tepat sesuai dengan daya beli masyarakat mempengaruhi keinginan pembelian akan suatu produk yang memang diinginkan oleh konsumen. Harga berpengaruh negartif dan signifikan terhadap kepuasan konsumen, berarti harga yang semakin rendah produk yang ditawarkan toko, maka kepuasan konsumen akan semakin tinggi. Sehingga dari beberapa pernyataan diatas, maka dirumuskan hipotesis yaitu semakin murah harga barang dan tingginya minat beli, maka semakin tinggi kepuasan konsumen.

Perilaku konsumen dari seorang muslim dalam memaksimalkan kepuasan. Terdapat batasan syariat dalam konsumsi seorang muslim, tidaklah cukup hanya dengan anggaran. Batasan tersebut antara lain mengkonsumsi produk haram, penghasilan dari kegiatan yang tidak halal, menerima riba dan kewajiban mengeluarkan zakat. Faktor kebudayaan, sosial pribadi dan psikologis secara simultan berpengaruh terhadap keputusan pembelian, sedangkan faktor kebudayaan dan sosial tidak berpengaruh terhadap keputusan pembelian. Dari beberapa penelitian sebelumya maka semakin baik perilaku konsumen muslim dan tingginya minat beli, maka semakin tinggi kepuasan konsumen.

\section{HASIL DAN PEMBAHASAN}

\section{A. Analisis Deskriptif Responden}

Penelitian ini dilakukan kepada konsumen di toko bernuansa muslim di Salatiga. Total responden yang digunakan peneliti berjumlah 97 orang dengan berbagai jenis latar belakang yang berbeda-beda. Penjelasan dan deskripsi responden sebagai berikut :

\section{Jenis Kelamin}


Tabel 1. Klasifikasi Responden Berdasarkan Jenis Kelamin

\begin{tabular}{|l|l|r|r|r|r|}
\hline \multicolumn{7}{|c|}{ Jenis Kelamin } \\
\hline \multicolumn{2}{|c|}{} & Frequency & Percent & $\begin{array}{c}\text { Valid } \\
\text { Percent }\end{array}$ & $\begin{array}{c}\text { Cumulative } \\
\text { Percent }\end{array}$ \\
\hline \multirow{3}{*}{ Valid } & Laki-Laki & 16 & 16,0 & 16,0 & 16,0 \\
\cline { 2 - 6 } & Perempuan & 81 & 84,0 & 84,0 & 100,0 \\
\cline { 2 - 6 } & Total & 97 & 100,0 & 100,0 & \\
\hline
\end{tabular}

Sumber : Data primer yang diolah, 2020

Dari tabel diketahui bahwa responden berjenis kelamin Laki-laki berjumlah 16 orang $(16 \%)$ dan responden Perempuan berjumlah 81 orang $(84 \%)$ dari total responden. Bisa disimpulkan bahwa responden Perempuan mendominasi dalam penelitian ini.

2. Pekerjaan

Tabel 2. Klasifikasi Responden Berdasarkan Jenis Pekerjaan

\begin{tabular}{|l|l|r|r|r|r|}
\hline \multicolumn{5}{|c|}{ Pekerjaan } \\
\hline \multirow{4}{*}{ Valid } & Frequency & Percent & $\begin{array}{c}\text { Valid } \\
\text { Percent }\end{array}$ & $\begin{array}{c}\text { Cumulative } \\
\text { Percent }\end{array}$ \\
\cline { 2 - 6 } & $\begin{array}{l}\text { Pelajar/ } \\
\text { Mahasiswa }\end{array}$ & 5 & 5,0 & 5,0 & 5,0 \\
\cline { 2 - 6 } & PNS & 11 & 11,0 & 11,0 & 16,0 \\
\cline { 2 - 6 } & Karyawan & 22 & 23,0 & 23,0 & 39,0 \\
\cline { 2 - 6 } & Lainnya & 29 & 30,0 & 30,0 & 69,0 \\
\cline { 2 - 6 } & Wiraswasta & 30 & 31,0 & 31,0 & 100,0 \\
\cline { 2 - 6 } & Total & 50 & 100,0 & 100,0 & \\
\cline { 2 - 6 } & & & & & \\
\hline
\end{tabular}

Sumber : Data primer yang diolah, 2020

Dari tabel diketahui bahwa responden dengan latar belakang Pelajar/Mahasiswa berjumlah 5 orang (5\%), pekerjaan PNS berjumlah 11 orang (11\%), Karyawan berjumlah 22 orang (23\%), Wiraswasta 30 orang (31\%), dan pekerjaan Lainnya berjumlah 29 orang (30\%). Bisa disimpulkan pekerjaan wiraswasta paling dominan.

3. Usia

Tabel 3. Klasifikasi Responden Berdasarkan Usia

\begin{tabular}{|l|l|r|r|r|r|}
\hline \multicolumn{2}{|c|}{} & & & & \\
\hline \multicolumn{2}{|c|}{} & Frequency & Percent & Valid Percent & $\begin{array}{c}\text { Cumulative } \\
\text { Percent }\end{array}$ \\
\hline \multirow{4}{*}{ Valid } & $11-20 \mathrm{Th}$ & 5 & 6,0 & 6,0 & 6,0 \\
\cline { 2 - 6 } & $21-30 \mathrm{Th}$ & 25 & 26,0 & 26,0 & 32,0 \\
\cline { 2 - 6 } & $31-40 \mathrm{Th}$ & 37 & 38,0 & 38,0 & 70,0 \\
\cline { 2 - 6 } & $41-50 \mathrm{Th}$ & 29 & 30,0 & 30,0 & 100,0 \\
\cline { 2 - 6 } & Total & 97 & 100,0 & 100,0 & \\
\hline
\end{tabular}

Sumber : Data primer yang diolah, 2020

Dari tabel diketahui bahwa responden dengan latar belakang usia $11-20$ tahun berjumlah 5 orang $(6 \%)$, usia $21-30$ tahun berjumlah 25 orang (26\%), usia $31-40$ tahun berjumlah 37 orang (38\%), usia 41 - 50 tahun berjumlah 29 orang (30\%) dan tidak ada responden dengan usia di atas 50 tahun.

4. Pendapatan 
Tabel 4. Klasifikasi Responden Berdasarkan Pendapatan

\begin{tabular}{|l|l|r|r|r|r|}
\hline \multicolumn{2}{|c|}{ Pendapatan } \\
\hline \multicolumn{2}{|l|}{} & Frequency & Percent & $\begin{array}{c}\text { Valid } \\
\text { Percent }\end{array}$ & $\begin{array}{c}\text { Cumulative } \\
\text { Percent }\end{array}$ \\
\hline Valid & $\begin{array}{l}\text { Rp. 500.0000 sampai } \\
\text { Rp. 2.000.000 }\end{array}$ & 8 & 8,0 & 8,0 & 20,0 \\
\cline { 2 - 6 } $\begin{array}{l}\text { Rp. 1.000.000 sampai } \\
\text { Rp. 2.500.000 }\end{array}$ & 46 & 46,0 & 46,0 & 66,0 \\
\hline $\begin{array}{ll}\text { Rp 2.500.000 sampai } \\
\text { Rp. 5.000.000 }\end{array}$ & 37 & 37,0 & 37,0 & 94,0 \\
\cline { 2 - 6 } $\begin{array}{l}\text { Rp. 5.000.000,- sampai } \\
\text { Rp 10.000.000 }\end{array}$ & 6 & 6,0 & 6,0 & 100,0 \\
\cline { 2 - 6 } & Total & 97 & 100,0 & 100,0 & \\
\hline
\end{tabular}

Sumber : Data primer yang diolah, 2020

Dari tabel di atas diketahui bahwa responden dengan pendapatan Rp. $500.000-\mathrm{Rp}$. 1.000 .000 berjumlah 8 orang (8\%), pendapatan Rp. 1.000 .000 - Rp. 2.500 .000 berjumlah 46 orang (46\%), pendapatan Rp. 2.500 .000 - Rp. 5.000 .000 berjumlah 37 orang (37\%) dan pendapatan Rp. 5.000.000 sampai Rp 10.000.000 berjumlah 6 orang (6\%). Bisa disimpulkan bahwa responden dengan pendapatan Rp. 1.000 .000 - Rp. 2.500 .000 mendominasi jenis responden.

Tabel 5. Hasil Hipotesis Penelitian

\begin{tabular}{|l|l|c|l|}
\hline \multicolumn{1}{|c|}{ Hipotesis } & Uji t & Sig & Keterangan \\
\hline H1 Lokasi dan minat beli terhadap kepuasan konsumen & - & 0,000 & Diterima \\
\hline $\begin{array}{l}\text { H2 Keragaman Produk dan minat beli terhadap kepuasan } \\
\text { konsumen }\end{array}$ & $\begin{array}{l}- \\
1,440\end{array}$ & 0,153 & Ditolak \\
\hline H3 Harga dan minat beli terhadap kepuasan konsumen & - & 0,009 & Diterima \\
\hline $\begin{array}{l}\text { H4 Perilaku Konsumen Muslim dan minat beli terhadap } \\
\text { kepuasan konsumen }\end{array}$ & $\begin{array}{l}- \\
1,819\end{array}$ & 0,072 & Ditolak \\
\hline
\end{tabular}

\section{KESIMPULAN} berikut:

Berdasarkan hasil penelitian dan pembahasan, maka dapat ditarik kesimpulan sebagai

1) Untuk mendapatkan tingkat kepuasan konsumen yang tinggi faktor lokasi usaha menjadikan faktor yang penting agar menarik minat konsumen. Lokasi yang strategis menjadikan daya tarik tersendiri bagi calon konsumen.

Dari hasil penelitian variabel lokasi dan minat beli sebagai mediator berpengaruh terhadap kepuasan konsumen.

2) Pemilik usaha sebaiknya memperhatikan keberagaman produk dari barang dan cara penyajian produk baik itu letak maupun kondisi dari produk yang disajikan agar menarik minat konsumen dan konsumen bisa menjadi puas.

Dari hasil penelitian variabel keberagaman produk dan minat beli sebagai mediator tidak berpengaruh terhadap kepuasan konsumen.

3) Proses penentuan harga suatu barang haruslah dilakukan dengan hati-hati dan menjadi sangat penting karena akan mempengaruhi minat beli konsumen, yang pada akhirnya akan berpengaruh terhadap kepuasan konsumen. 
Dari hasil penelitian variabel harga dan minat beli sebagai mediator berpengaruh terhadap kepuasan konsumen.

4) Perilaku konsumen muslim menjadikan pemilik usaha atau toko harus lebih berhati-hati dalam memilih produk yang dijual, system pembayaran karena spesikikasi dari konsumen muslim berbeda dengan yang lain.

Dari hasil penelitian variabel perilaku konsumen muslim dan minat beli sebagai mediator tidak berpengaruh terhadap kepuasan konsumen.

\section{KETERBATASAN PENELITIAN}

1. Sampel dalam penelitian ini hanya terbatas pada toko dan belum mencakup semua toko kelontong di Salatiga seara keseluruhan. Akan lebih baik lagi bila sampel yang diambil dari segi yang lebih luas lagi.

2. Penelitian yang meliputi beberapa variabel mungkin bisa ditambah dengan variabel lain yang bisa mempengaruhi perbedaan penelitian, segi pelayanan toko, kualitas produk dan store athmosphere.

3. Quesioner perlu disajikan lebih teliti, mendetail sehingga akan bisa menghasilkan hasil data dan penyajian yang lebih mendalam.

\section{SARAN}

Berdasarkan hasil penelitian dan pembahasan dan kesimpulan yang diperoleh, maka ada beberapa saran yang diberikan sebagai berikut:

1. Maksud dan tujuan seseorang muslim berbelanja di toko selain untuk memenuhi kebutuhan yang diharapkan, juga untuk membantu sesama muslim lain. Dari hasil atau laba yang diperoleh pemilik toko agar amanah untuk menyisihkan zakat yang digunakan untuk saling membantu antar sesama muslim. Ekonomi sesama muslim bisa menjadi kuat dengan membeli dan berbelanja di toko seorang muslim.

2. Penelitian berikutnya bisa menggunakan metode lain dalam meneliti faktor lokasi, keberagaman produk dan faktor-faktor lainnya.

\section{DAFTAR PUSTAKA}

A.A. Anwar Prabu Mangkunegara, Perilaku konsumen, Bandung: Refika Aditama, 2002

Abdul Shomad, Hukum Islam: Penormaan Prinsip Syariah Dalam Hukum Indonesia, Edisi Revisi, Jakarta Kencana 1997

Adhiyatma Firmansyah, " Pengaruh Lokasi, Harga, Fasilitas dan Kualitas Pelayanan Terhadap Kepuasan Konsumen" Skripsi, Universitas Muhammadiyah Surakarta, 2018

Achmad Zanul Arif, "Pengaruh Keberagaman Produk, Kualitas Produk dan Lokasi Terhadap Minat Beli Konsumen di Pasar Pabean Surabaya", Universitas Narotoma Surabaya, 2017

Arif Purnomo Aji, "Analisis Pengaruh Harga, Lokasi dan Keragaman Produk Terhadap Minat Beli di Luwes Delanggu", Universitas Muhammadiyah Surakarta, skripsi 2017

Astika Pratiwi, "Pengaruh Lokasi, Harga dan Keberagaman Produk Terhadap Minat Beli Pada Pasar Tradisional Argosari Wonosari", UNY Yogjakarta, 2016.

Azwar, Reabilitas dan Validitas, Edisi 3; Yogyakarta: Pustaka Pelajar, 2002.

Ajzen, I The Theory of Planned behavior, Organizational Behavior and Human Decision Processes, 1991.

Dinawan. R. M. “Analisis Faktor-faktor Yang Mempengaruhi Keputusan Pembelian (Studi Kasus Pada Konsumen Yamaha Mio PT Harpindo Jaya Semarang). Tesis, Universitas Diponegoro Semarang, 2010. 
William Doods, B, Monroe, Kent B, Grewal, Dhruv; Effect of Prece, Brand and Store Information on Buyer's Product Evaluation, "Journal of Marketing Reseach", Vol XXVIII, Agustus 1991.

Eka Kiki febriana, "Pengaruh Keragaman Produk, Kualitas Produk dan Lokasi Penjualan Terhadap Kepuasan Konsumen" Skripsi, Universitas Pandanaran Semarang, 2017

Githa Bannazirlie, "Faktor-Faktor Yang Mempengaruhi Minat Konsumen Belanja di Pasar Modern" thesis, IAIN Syekh Nurjati, Cirebon, 2012.

Haris Ilham, "Pengaruh Tingkat Religiusitas, Kualitas Pelayanan, dan Kepercayaan Terhadap Minat Masyarakat Menabung di Bank Syariah Dengan Minat Sebagao Variabel Moderasi" skripsi, IAIN Salatiga, 2019.

Hendra Fure, "Lokasi, Keberagaman Produk, Harga Dan Kualitas Pelayanan Pengaruhnya Terhadap Minat Beli Pada Pasar Tradisional Bersehati Calaca. Manado", Jurnal EMBA Vol.1 No.3 September 2013 hal 1768-1780.

Hetty Sri Wardani, "Pengaruh Kualitas Produk dan Harga Terhadap Minat Beli Konsumen Muslim Pada Jaizah Boutique Tlogosari Semarang" thesis UIN Walisongo 2015

Herry Novrianda, Analisis pengaruh kualitas produk, kualitas layanan dan harga terhadap kepuasan konsumen, journal Baabu Al-Ilmi Vol. 1 No 2Oktober 2016, hal 80-93

Husein Umar, Metode Penelitian Untuk Skripsi dan Tesis , Jakarta; PT Grafindo Persada, 2013

Idri, Hadis Ekonomi: Ekonomi Dalam Perspektif Hadis Nabi, Jakarta, Prenadamedia Group, 2015

Ika Yunia Fauzia, Etika Bisnis Dasar Islam, Cet, II. Jakarta: Kencana Pranadamedia Group, 2014

Imam Ghazali. Aplikasi Analisis Multivariate dengan Program SPSS. Edisi Keempat, Penerbit Universitas Diponegoro,2010

Inggrid Panjaitan “ Pengaruh Pelayanan Dan Harga Pada Go-Jek Terhadap Kepuasan Konsumen Dengan Minat Sebagai Variabel Moderating” Jurnal Media Studi Ekonomi, Vol 19 No 2 Juli-Desember, 2016, hal 43-55.

Iwan Setiawan, Pengembangan Bisnis Tanpa Riba, Jurnal Tahkim, Volume XIII No 2 Desember 2017, hal17-30

Jonathan Herdioko, "Pengaruh Produk Dan Harga Tehadap Minat Beli Konsumen Dalam Berbelanja Produk Kopi Secara Daring: Studi Kasus Pada Situs Internet Otten Coffee, Jurnal Riset Manajemen dan Bisnis,Vol 12, No 2 2017, hal 129-136.

Kinear, Thomas C and James R T aylor, Marketing Reseach: An Apllied Approach. McGraw Hill Text, 1995.

Kismono G, Pengantar Bisnis, Jakarta : BPFE, 2001

Phillip Kotler, Manajemen Pemasaran Analisis Perencanaan Implementasi Kontrol, Jilid I, Jakarta:Prehallindo, 1997.

Philip Kotler, Manajemen Pemasaran, Edisi Milenium. Jakarta: PT Prehallindo, 2002.

Linda Sari, "Faktor-Faktor Yang Mempengaruhi Konsumen Muslim Membeli Produk Tanpa Label halal", skripsi Universitas Islam Negeri Sumatera Utara, 2018.

Lewis, Gregory, Taktik Menetapkan Harga/Pricing For Profit. Jakarta: Gramedia, 1997

Mardani, Hukum Sistem Ekonomi Islam, jakarta, PT Rajagrafindo Persada, 2015

M A Mannan (ed) Teori dan Praktek Ekonomi Islam, diterjemahkan oleh Sohaji dan Karnaen Perwataatmaja, et al dari "Islamic Economics; Theory and Practice", Yogyakarta:PT Dana Bhakti Wakaf, 1993.

M Nur Rianto Al Arif\&Euis Amalia, Teori Mikroekonomi Suatu Perbandingan Ekonomi Islam dan Ekonomi Konvensional I Cetakan ke 1; Jakarta:Kencana, 2010

M Nur Rianto, “ Perilaku Konsumen Muslim Dalam Memaksimumkan Kepuasan” jurnal SosioReligius LinkSas Yogyakarta, Vol. 9 No 2 tahun2010, hal 1-16

Mardikasari, "Pengaruh Store Atmosphere, Lokasi Toko dan Keberagaman Produk Terhadap Keputusan Pembelian Konsumen Mirota Kampus”, S1 thesis, 2013.

Muhamad Hanafi, Prinsip dan Etika Bisnis Dalam Islam, Suatu Sorotan Etika Bisnis Rasulullah SAW Jakarta: Pustaka Antara, 1992. 
Muhamad Husni Handri, Jhon Fernos, "Pengaruh Suasana Toko Dan Lokasi Terhadap Minat Bel i Konsumen Pada Minimarket Xmart Ulak Karang Padang, Skripsi STIE KBP Padang, 2018.

Muhamad Muflih, Perilaku Konsumen dalam Perspektof Ilmu Ekonomi Islam, PT Dana Bhakti Prima Yasa, 1997.

Muhammad, Ekonomi Mikro dalam perspektif Islam, Yogyakarta:BPFE, 2004.

Oetomo, Rahardian A dan Nugraheni, Rini, "Analisis Pengaruh Keberagaman Menu, Persepsi Harga dan Lokasi Terhadap Minat Beli Ulang Konsumen" Skripsi, Universitas Dipenegoro, 2012.

Putong, Iskandar, PengantarMikro dan Makro, Edisi Kelima, Mita Wacana Media, Jakarta, 2013.

Prasetiyo, "Pengaruh Kualitas Pelayanan dan Harga Terhadap Kepuasan Pelanggan" Skripsi 2012.

Rahmat Nur Riandika, "Pengaruh Lokasi, Harga Dan Keragaman Produk Terhadap Keputusan Pembelian di Mall Dinoyo City", Jurnal riset Manajemen Fakultas Ekonomi Unisma, 2017, hal 50-64.

Rika Andriyani, "Analisis Penerapan Prinsip-Prinsip Syariah Pada Bisnis Ritel Syariah di Minimarket Sakinah 212 Mart Wonorejo Tandes Surabaya,skripsi, UIN Surabaya, 2019

Sakti, Ali, Sistem Ekonomi Islam Filosofi dan Bangunannnya, 2003

Setiyanto, "Analisis Hubungan Harga dan Pelayanan Dengan Kepuasan Konsumen, Studi Kasus : CV Nanda Group Car Rental Yogyakarta" Sripsi Universitas Sanata Dharma, 2010.

Sopiyah dan Syihabuddin, Manajemen BisnisRitel, Andi, Yogyakarta,2010.

Sugiyono, Memahami Metode Kualitatif, Bandung CV Alvabeta, 2015.

Suryani dan Hendryadi, Metode Riset Kuantitatif (Teori Penelitian bidang Manajemen dan Ekonomi Islam) Edisi Pertama; Jakarta: Prenadamedia Group, 2015

Swastha Basu, Azaz-azaz Marketing, Yogyakarta: Liberty 2002

Swastha dan Handoko, Manajemen Pemasaran Analisis Perilaku Konsumen, Yogyakarta, BPFE 2000.

Swastha, Basu dan Irawan, Manajemen Pemasaran Modern, Yogyajarta:BPFE, 2001.

Tjiptono, Fandy. Pemasaran Jasa, Bayumedia: Malang, 2006.

Umar, Metode Penelitian Kualitatif dan Kuantitatif, Cetakan 2; Jakarta: Bumi Angkasa, 2014.

Wahyunita Nur, "Pengaruh Lokasi, Keberagaman Produk dan Harga Terhadap Minat Beli Pada Giant Express Allaudin Makasar" skripsi Universitas Alauddin Makasar, 2016.

Toni Wijaya, Metodologi Penelitian Ekonomi dan Bisnis, Yogjakarta;Graha Ilmu, 2013.

Yamin dan Kurniawan, Pengantar Analisis Jalur (Path Analysis), Salemba 2014

Yuli Mutiah Rambe dan Syaad Afifuddin, "Pengaruh Pencantuman Label Halal Pada Kemasan Mie Instan Terhadap Minat Pembelian Masyarakat Muslim", Jurnal Ekonomi dan Keuangan, Vol 1, No1 Desember 2012.

Yusuf Qadarwi, Norma Dan Etika Ekonomi Islam, diterjemahkan oleh Zainal Arifin,Lc. Cetakan ke-2, Jakarta: Gema Insani Perss, 1999 